\title{
Histological and Scanning Electron Microscopic Examination of the Digestive Tract in Whitespotted Conger, Conger Myriaster (Anguilliformes)
}

\section{Shunpei Takiue ${ }^{1,2}$ and Hideo Akiyoshi ${ }^{1 *}$}

${ }^{1}$ Department of Biological Science, Faculty of Life and Environmental Science, Shimane University, 1060 Nishikawatsu, Matsue 690-8504, Japan

${ }^{2}$ The United Graduate School of Agricultural Sciences, Tottori University, 4-101 Koyama-Minami, Tottori 680-8553, Japan

\begin{abstract}
The morphology of the digestive tract of Whitespotted conger, Conger myriaster (Elopomorpha: Anguilliformes) was examined by light and scanning electron microscopy. The digestive tracts consist of esophagus, stomach, and intestine; no pyloric caeca were observed. The stomach was divided into cardiac, body, terminal and pyloric region. The esophagus was composed of two layers of striated muscularis; inner longitudinal layer and outer circular layer. The former was extended to the body region of the stomach. In contrast, the latter was terminated to the esophagus, and became coincident to the boundary of the outer longitudinal layer consisting of smooth muscle in the cardiac region of the stomach. The terminal region of the stomach was characterized by the thick longitudinal muscularis and subserosa, and the gastric glands were absent. Ciliated cells were distributed in the intestinal wall. The digestive tract secreted both acidic and neutral mucus throughout all regions. We found that the terminal region of the stomach is characteristic of Anguilliformes. On the other hand, the striated muscle within the body region of the stomach was unique among the Anguilliformes. These differences in stomach suggested the possible existence of morphological differences that originate from phylogenetic position among the orders in Elopomorpha.
\end{abstract}

Keywords: Elopomorpha; Anguilliformes; Whitespotted conger; Digestive tract; Histochemistory; Scanning electron microscopy; Phylogeny

\section{Introduction}

Elopomorpha comprise a phylogenetically unique species that form a bridge between the basal and higher teleosts. The species within the orders Elopiformes, Albuliformes, Anguilliformes and Saccopharyngiformes [1-3] have undergone considerable adaptive radiation, making members of the Elopomorpha well suited for evolutionary studies. The Anguilliformes are the most diverse order in the Elopomorpha. Its members are classified into three suborders: the Muraenoidei, Congroidei, and Anguilloidei $[1,4]$ and are found in a wide range of habitats from equatorial to polar regions, mountain streams to the ocean floor, and seawater to freshwater environments. The feeding habits are similarly diverse with Anguilliformes occupying an important position for the examination of phylogenetic evolution of the digestive system.

The digestive tract in Elopomorpha is characteristic of that in teleosts; some possess both a stomach and the pyloric caeca [5], while basal teleosts in Elopomorpha have a large blind sac stomach only with no pyloric caeca [6-8]. In the Elopomorpha, the stomach in Anguilloidei is histologically divided into the cardiac, fundus, and pyloric regions [9,10], and in Gymnothoraxpictus [Muraenoidei], the stomach forms the characteristic terminal region within the blind sac stomach [8]. The terminal region of the stomach is characterized by thick longitudinal muscularis and subserosa layers, and gastric glands are absent. It is considered that the histological structure of this region is associated with the transport of large food items [8]. The pyloric region also lacks gastric glands and this region possesses the thickest inner circular muscle layer in the stomach $[8,9,11]$.

The intestines in Anguilloidei are separated from the rectum by an ileo-rectal valve $[9,12]$, and several partition-like mucosal folds are observed within the posterior intestine of G. pictus [8], but are absent in Anguilloidei [12]. Scanning electron microscopy (SEM) images show that microvilli are densely distributed as a brush border on the apical surface of mucosal epithelial cells [8,9]. In G. pictus, ciliated cells are present between enterocytes [8], but these are not observed in Anguilloidei.
The mucosa of the digestive tract usually secretes mucus onto the luminal surface. The gastric surface mucous cells in Anguilloidei produce both acidic and neutral mucus [9-11], and this is the same as for the stomach, including the terminal region in G. pictus [8]. The mucus within intestinal goblet cells in Anguilloidei also consists of a combination of acidic and neutral secretions $[10,13]$, but those in $G$. pictus contain only acidic secretions [8].

Thus, the tissues and the cells that compose the digestive tract differ among species in Anguilloidei and Muraenoide in Anguiiliformes, and there are phylogenetic differences among orders in Elopomorpha. However, the current anatomical and histological knowledge of the digestive tract of species belonging to Anguilliformes is still limited to orders of Anguilloidei and Muraenoidei, whereas the Congroidei, which are phylogenetically positioned between these two suborders, have not yet been sufficiently investigated.

In the present study, we examined histological and histochemical features of the digestive tract of the Whitespotted conger, Conger myriaster (C.myriaster) (Brevoort, 1856) (Congridae; Conger) by light microscopy and SEM, and discuss the findings within the context of the evolution of the digestive tract in the Elopomorpha.

\section{Materials and Methods}

The study protocol was approved by the animal ethics committee of Shimane University, and was conducted in strict adherence with the guidelines for the care and use of research animals set out by the committee.

*Corresponding author: Hideo Akiyoshi, Department of Biological Science, Faculty of Life and Environmental Science, Shimane University, 1060 Nishikawatsu, Matsue 690-8504, Japan, Tel: +81-852-32-6440, E-mail: akiyoshi@life.shimane-u.ac.jp

Received May 12, 2014; Accepted May 27, 2014; Published June 03, 2013

Citation: Takiue S, Akiyoshi H (2014) Histological and Scanning Electron Microscopic Examination of the Digestive Tract in Whitespotted Conger, Conger Myriaster (Anguilliformes). J Phylogen Evolution Biol 2: 125. doi:10.4172/23299002.1000125

Copyright: $\odot 2014$ Takiue S, et al. This is an open-access article distributed under the terms of the Creative Commons Attribution License, which permits unrestricted use, distribution, and reproduction in any medium, provided the original author and source are credited. 
Citation: Takiue S, Akiyoshi H (2014) Histological and Scanning Electron Microscopic Examination of the Digestive Tract in Whitespotted Conger, Conger Myriaster (Anguilliformes). J Phylogen Evolution Biol 2: 125. doi:10.4172/2329-9002.1000125

\section{Sample collection}

Twelve Whitespotted congers, C. myriaster, were collected between 2003 and 2012 and between the months of June and November for morphological examination from the catches of fishing nets in Nakaumi, Shimane Prefecture, Japan. In order to control for the influence of seasonal differences and growth stages, only adult-stage specimens were used [total body length (TL), $54.7 \pm 3.37 \mathrm{~cm}$ and total weight, $233.8 \pm 36.58 \mathrm{~g}]$. The conger eels were maintained in glass tanks with running water under optimal oxygenation conditions, and the temperature was maintained at $24.0 \pm 1.0^{\circ} \mathrm{C}$ throughout the 3 -day experimental period.

\section{Tissue preparation}

The conger eels were anesthetized by an overdose of $0.05 \%$ tricaine methane sulfonate (MS-222: Sigma-Aldrich, Tokyo, Japan) in the holding water. The digestive tract tissues of each eel were perfusion-fixed via the heart with either $4 \%$ paraformaldehyde in $0.1 \mathrm{M}$ phosphate buffer, $\mathrm{pH}$ 7.4 or with $1.5 \%$ glutaraldehyde in $0.1 \mathrm{M}$ phosphate buffer, $\mathrm{pH} 7.4$ over a period of $15 \mathrm{~min}$. The lumen of each specimen was subsequently washed and perfused with the same solution, and the entire digestive tractwas immersed in the fixing solution for 3 days at $4^{\circ} \mathrm{C}$. Prior to analysis, small pieces of the esophagus, stomach (cardiac, body, terminal, and pyloric), and intestine (anterior and posterior regions) were excised from the digestive tract and fixed in each of the fixative solutions.

\section{Light microscopy}

Excised samples of digestive tract samples fixed in $4 \%$ paraformaldehyde were rinsed, dehydrated, and embedded in paraffin wax. Serial $4 \mu \mathrm{m}$ sections were prepared and stained with hematoxylin and eosin (H\&E), and histochemical staining was performed for mucus detection. Sections were stained with Alcian blue, $\mathrm{pH}$ 2.5/Periodic acidSchiff (AB/PAS) after glycogen digestion by diastase. In this method, neutral mucus is stained red and acidic mucus is stained blue. Sections were observed and photographed with a BX51 photomicroscope (Olympus, Tokyo, Japan).

\section{Scanning electron microscopy}

Excised samples of digestive tract samples fixed with $1.5 \%$ glutaraldehyde were rinsed, dehydrated, conductive-stained by $2.0 \%$ tannic acid and $1.0 \%$ osmium tetroxide, and freeze-dried with t-butyl alcohol. Samples were subsequently sputter coated with platinum and observed under a digital scanning electron microscope (S-4800; Hitachi High-Technologies Corp., Tokyo, Japan).

\section{Results}

\section{Anatomical observations}

Digestive tracts were composed of an esophagus, a stomach, and an intestine (Figure 1a). No caeca were observed in the pyloric region of the stomach. The mean length of the esophagus was $3.3 \pm 1.06 \mathrm{~cm}$, and the color was white. The stomach was divided into four regions for examination: the cardiac region continuous with the esophagus, the long saccular body with a terminal region, and the pyloric region continuous with the intestine. The color of the terminal region of the stomach was white and clearly differed from that of the body region (Figure 1b). The intestine was short and almost straight; the mean length was $13.7 \pm 3.53$ $\mathrm{cm}$ and its ratio to TL was $0.26 \pm 0.06$. The mucosal folds within the posterior intestine were shorter than those in the anterior intestine; the transition from the posterior to the anterior intestine was clear. Only one partition-like mucosal fold was observed within the terminal side of the posterior intestine in all individuals (Figure 1c). The ileo-rectal valve, which is created by two mucosal folds, was observed posterior to the partition-like mucosal fold.

\section{Histological observations}

Esophagus: The esophagus was composed of four layers: mucosa, submucosa, muscularis, and serosa (Figure 2a). The majority of the mucosal folds were primary folds, and secondary folds were rare. The mucosal epithelium was composed of stratified cells, and numerous saccular mucous cells were observed individually on the surface (Figure $2 \mathrm{~b})$. The muscularis was composed of two layers: an inner longitudinal layer (Figure 2c) and an outer circular layer (Figure 2d), both of which were striated muscles. In SEM images, the apical surface of the polygonal mucosal epithelial cells showed fingerprint-like microridges (Figure 2e). Mucus secretion from saccular mucous cells was observed on surface of the mucosal epithelial cells.

Stomach: All regions of the stomach had four layers: mucosa, submucosa, muscularis, and serosa.

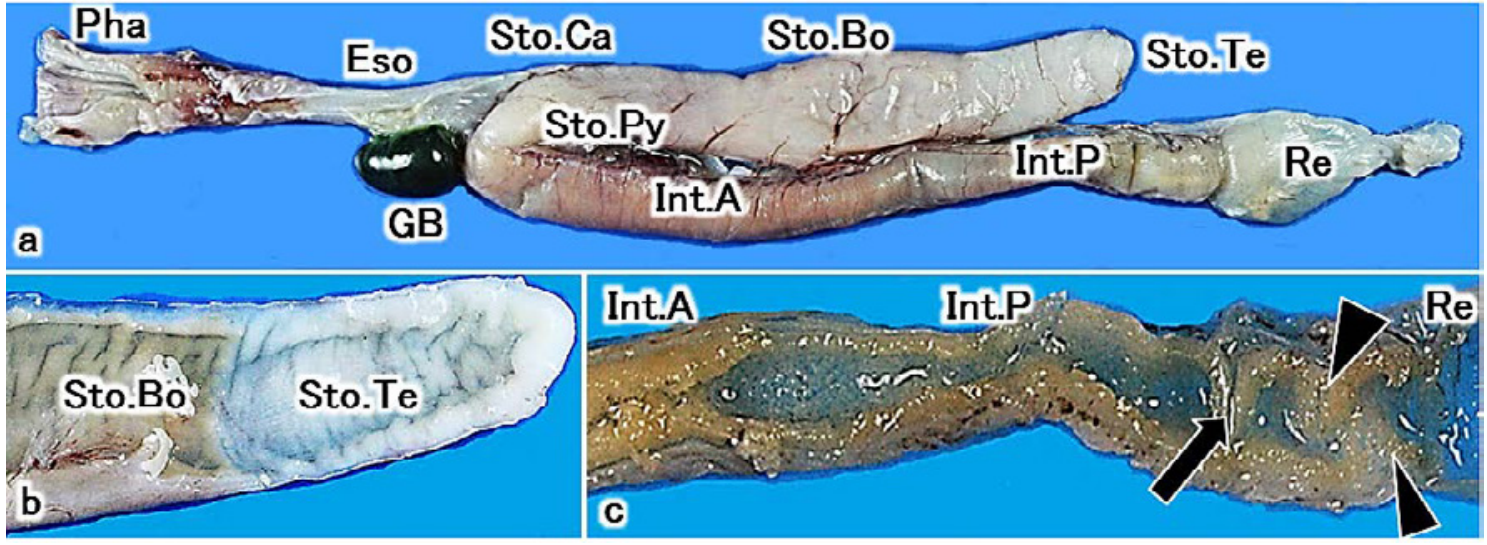

Figure 1: The digestive tract of Conger myriaster.

(a) Gross structures (accessory organs removed). The digestive tract was composed of an esophagus, a long saccular stomach, and a short straight intestine. (b) Sagittal section of the body-terminal region of the stomach. The terminal region of the stomach was white in color. (c) Sagittal section of the intestine- rectum. The partition-like mucosal fold (arrow) and the ileo-rectal valve (arrowhead) were observed. Eso, esophagus; GB, gall bladder; Int.A, anterior intestine; Int.P, posterior intestine; Pha, pharynx; Re, rectum; Sto.Bo, body region of stomach; Sto.Ca, cardiac region of stomach; Sto.Py, pyloric region of stomach; Sto.Te, terminal region of stomach. 


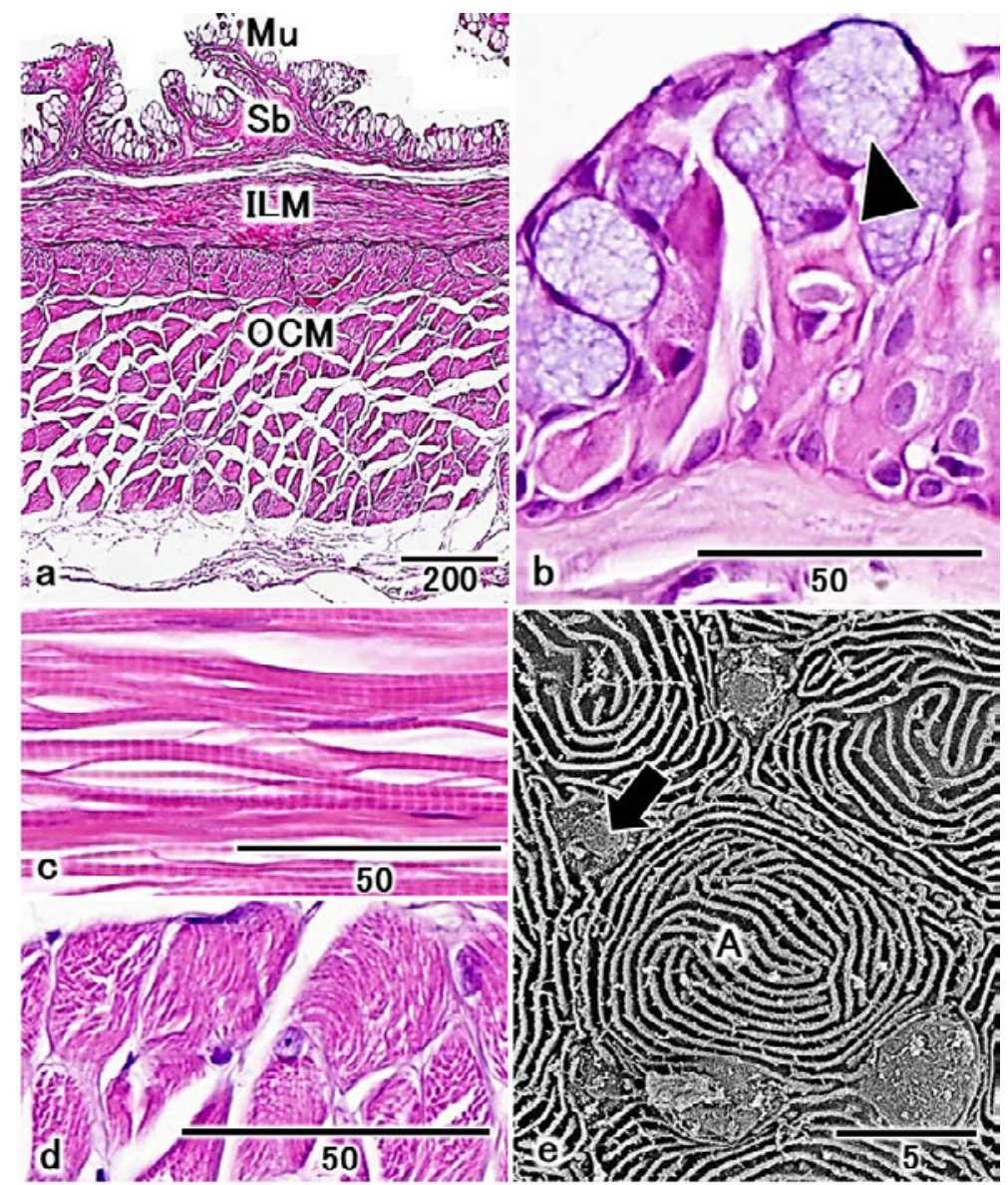

Figure 2: LM and SEM images in the esophagus. a-d: LM images, H\&E stain; e: SEM image.

(a) Whole sagittal section. Mucosa (Mu), submucosa (Sb), muscularis, and serosa were observed. Muscularis was composed of an inner longitudinal layer (ILM) and an outer circular layer (OCM). Scale bar $=200 \mu \mathrm{m}$. (b) Sagittal section of mucosa. Mucosal epithelium was composed of stratified cells and numerous saccular mucous cells (arrowhead). Scale bar $=50 \mu \mathrm{m}$. (c) Sagittal section of an inner longitudinal muscle layer. Striation was observed. Scale bar=50 $\mu \mathrm{m}$. (d) Sagittal section of an outer circular muscle layer. Striation was observed. Scale bar=50 $\mu \mathrm{m}$. (e) The apical surface of the polygonal mucosal epithelial cells (A) showed fingerprint-like microridges and secreted mucus (arrow) was observed between the mucosal epithelial cells. Scale bar $=5 \mu \mathrm{m}$.

Esophagus-Cardiac region of stomach. From the esophagus to the cardiac region of the stomach, cells comprising the mucosal epithelium transitioned from stratified cells mixed with saccular mucous cells to simple columnar cells (Figure 3a). The inner longitudinal striated muscle layer in the esophagus was present within the submucosa in the cardiac region of the stomach. In contrast, the outer circular striated muscle layer terminated at the boundary of the outer longitudinal smooth muscle layer in the cardiac region of the stomach.

Cardiac region of stomach: The mucosal epithelium of the cardiac region was composed of simple columnar cells, and no gastric glands were observed within the lamina propria. The muscularis was composed of inner longitudinal, middle circular and outer longitudinal layers (Figure $3 \mathrm{~b}$ ). The inner longitudinal layer consisted of striated muscle, and both the middle circular and outer longitudinal layers were smooth muscles.

Body region of stomach: The mucosal epithelium of the body region was composed of simple columnar cells, and gastric pits were observed between the cells (Figure 3c). Tubular gastric glands that opened at the base of the gastric pits were observed within the lamina propria. The muscularis was composed of inner longitudinal (Figure 3d), middle circular and outer longitudinal layers (Figure 3e). The inner longitudinal layer of muscle was striated, sparser than in the cardiac region of the stomach and was not observed in the submucosa. Both the middle circular and outer longitudinal layers consisted of smooth muscle. The circular layer was considerably thicker than the longitudinal layer, and it was a large part of the stomach wall.

Body-terminal region of stomach: Mucosal epithelial cells were present in both the body region and the terminal region of the stomach. However, the gastric glands were absent in the terminal region (Figure 3f).

Terminal region of stomach: The mucosal epithelium of the terminal region was composed of simple columnar cells, and the lamina propria lacked gastric glands. The muscularis was composed of inner circular and outer longitudinal layers (Figure 3g). Compared with each smooth muscle layer in the body region of the stomach, the inner circular layer was thin, but the outer longitudinal layer was considerably thicker. The subserosa was thick and the blood vessels were clearly visible within it.

Pyloric region of stomach: The mucosal epithelium of the pyloric region was composed of simple columnar cells, and no gastric glands were observed within the lamina propria. The muscularis was composed of inner circular and outer longitudinal layers. Compared with each smooth muscle layer in the body region of the stomach, the 
Citation: Takiue S, Akiyoshi H (2014) Histological and Scanning Electron Microscopic Examination of the Digestive Tract in Whitespotted Conger, Conger Myriaster (Anguilliformes). J Phylogen Evolution Biol 2: 125. doi:10.4172/2329-9002.1000125

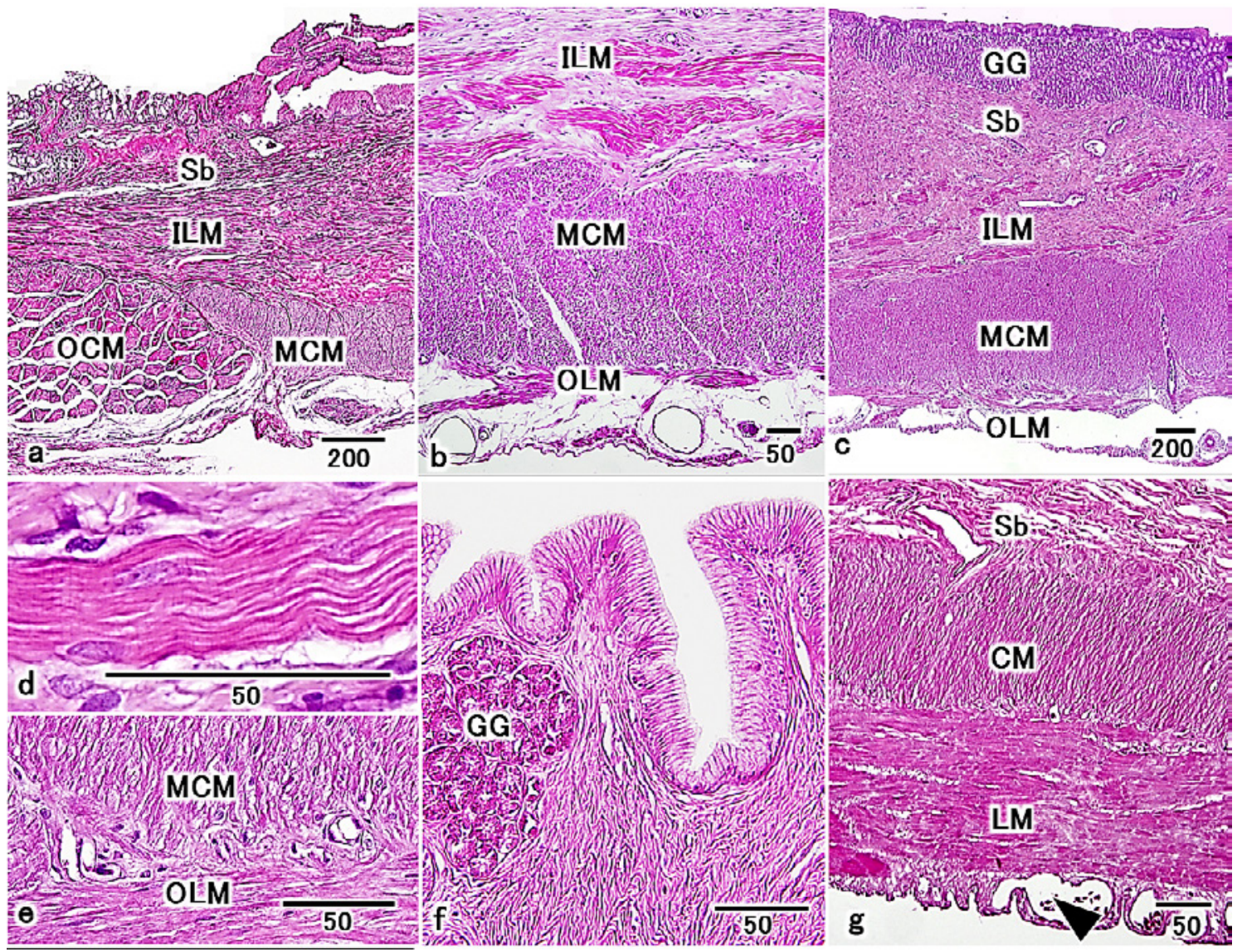

Figure 3: LM images in the esophagus- the terminal region of the stomach. H\&E stain.

(a) Sagittal section of the esophagus-the cardiac region of the stomach. Mucosa, submucosa (Sb), muscularis, and serosa were observed. The muscularis was composed of an inner longitudinal (ILM), a middle circular (MCM), and an outer longitudinal layers (OLM). OCM terminated and became coincident to MCM. Scale bar=200 $\mu \mathrm{m}$. (b) Sagittal section of muscularis in the cardiac region of the stomach. The muscularis was composed of an inner longitudinal (ILM), a middle circular (MCM), and an outer longitudinal layers (OLM). Scale bar=50 $\mu \mathrm{m}$. (c) Sagittal section of the body region of the stomach. Mucosa, submucosa (Sb), muscularis, and serosa were observed. Gastric glands (GG) were observed in lamina-propria. The muscularis was composed of an inner longitudinal (ILM), a middle circular (MCM), and an outer longitudinal layers (OLM). Scale bar=200 $\mu \mathrm{m}$. (d) Sagittal section of an inner longitudinal muscle layer in the body region of the stomach. Striation was observed. Scale bar=50 $\mu \mathrm{m}$. (e) Sagittal section of a middle circular muscle layer (MCM) and an outer longitudinal muscle layer (OLM) in the body region of the stomach. Each layer was composed of smooth muscle. Scale bar=50 $\mu \mathrm{m}$. (f) Sagittal section of mucosa in the body-terminal region of the stomach. Gastric glands (GG) in lamina-propria were disappeared from boundary. Scale bar=50 um. (g) Sagittal section of muscularis in the terminal region of the stomach. Thin inner circular layer (CM) and thick outer longitudinal layer (LM) were observed. Subserosa (Se) was thick and the blood vessels (arrowhead) were clearly visible within them. Submucosa $(\mathrm{Sb})$. Scale bar $=50 \mu \mathrm{m}$.

inner circular layer was much thicker, but the outer longitudinal layer was also thick.

Intestine: The anterior and posterior intestines were composed of the four basic layers: mucosa, submucosa, muscularis, and serosa.

Anterior intestine: Mucosal folds were highly branched; long secondary folds that appeared similar to branches were seen in Figure 4a. The mucosal epithelium was composed of simple columnar cells and a few goblet cells (Figure $4 \mathrm{~b}$ ). The muscularis was composed of inner circular and outer longitudinal layers. The inner circular layer was as thick as the outer longitudinal layer. SEM images revealed that the mucosal folds were composed of polygonal epithelial cells that were densely populated with microvilli forming a brush border on the apical surface, and the ciliary tufts of the ciliated cells were also observed between enterocytes (Figure 4c). The ciliated cells tended to be distributed on the tips of the mucosal folds.

Posterior intestine: Mucosal folds were less branched, and short primary folds were observed (Figure $4 \mathrm{~d}$ ). The mucosal epithelium was composed of simple columnar cells and numerous goblet cells (Figure 4e). The muscularis was composed of inner circular and outer longitudinal layers. Both layers were thinner than those of the anterior intestine. SEM images revealed that the mucosal folds were composed of polygonal epithelial cells that were densely populated with microvilli as a brush border on the apical surface, and the ciliary tufts of ciliated cells were observed between enterocytes (Figure 4f). The ciliated cells tended to be distributed on the tips of the mucosal folds, and the density was markedly higher within the posterior intestine than within the anterior intestine.

\section{Histochemical observations}

PAS staining after diastase digestion showed that glycogen was absent in mucous cells in all regions of the digestive tract examined. The gastric surface epithelial cells were stained different colors by $\mathrm{AB} /$ PAS stain depending on each region of stomach. In the cardiac region of stomach, the epithelial cells stained red-purple, indicating that a mixture of both acidic and neutral mucus was present in Figure 5a. But 
Citation: Takiue S, Akiyoshi H (2014) Histological and Scanning Electron Microscopic Examination of the Digestive Tract in Whitespotted Conger, Conger Myriaster (Anguilliformes). J Phylogen Evolution Biol 2: 125. doi:10.4172/2329-9002.1000125

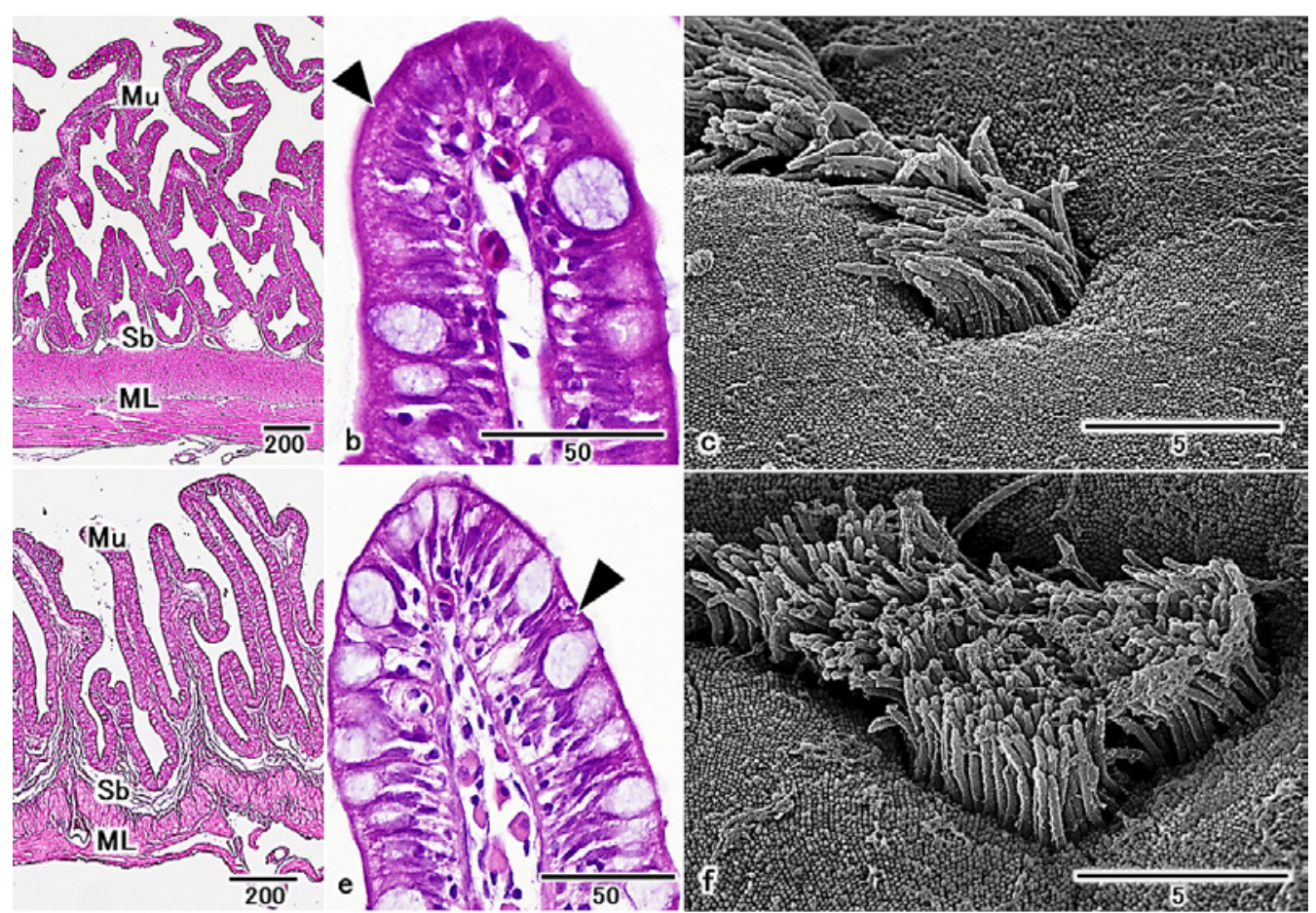

Figure 4: LM and SEM images in the intestine. a-c: the anterior region; d-f: the posterior region.

(a) LM image. Whole sagittal section. Mucosa (Mu), submucosa (Sb), muscularis (ML), and serosa were observed. Mucosal folds were secondary. H\&E stain. Scale bar=200 $\mu \mathrm{m}$. (b) LM image. Sagittal section of mucosal fold. Simple columnar epithelium cells and few goblet cells were observed. Brush border (arrow) was observed. H\&E stain. Scale bar=50 $\mu \mathrm{m}$. (c) SEM image. Ciliary tufts from ciliated cells were observed between microvilli. Scale bar=5 $\mu$ m. (d) LM image. Whole sagittal section. Mucosa $(\mathrm{Mu})$, submucosa $(\mathrm{Sb})$, muscularis $(\mathrm{ML})$, and serosa were observed. Mucosal folds were primary. H\&E stain. Scale bar=200 $\mu$ m. (e) LM image. Cross section of mucosa. Simple columnar epithelium cells and many goblet cells were observed. Brush border (arrow) was observed. H\&E stain. Scale bar $=50 \mu \mathrm{m}$. (f) SEM images. Ciliary tufts from ciliated cells between microvilli increased than the anterior region of intestine. Scale bar=5 $\mu \mathrm{m}$.

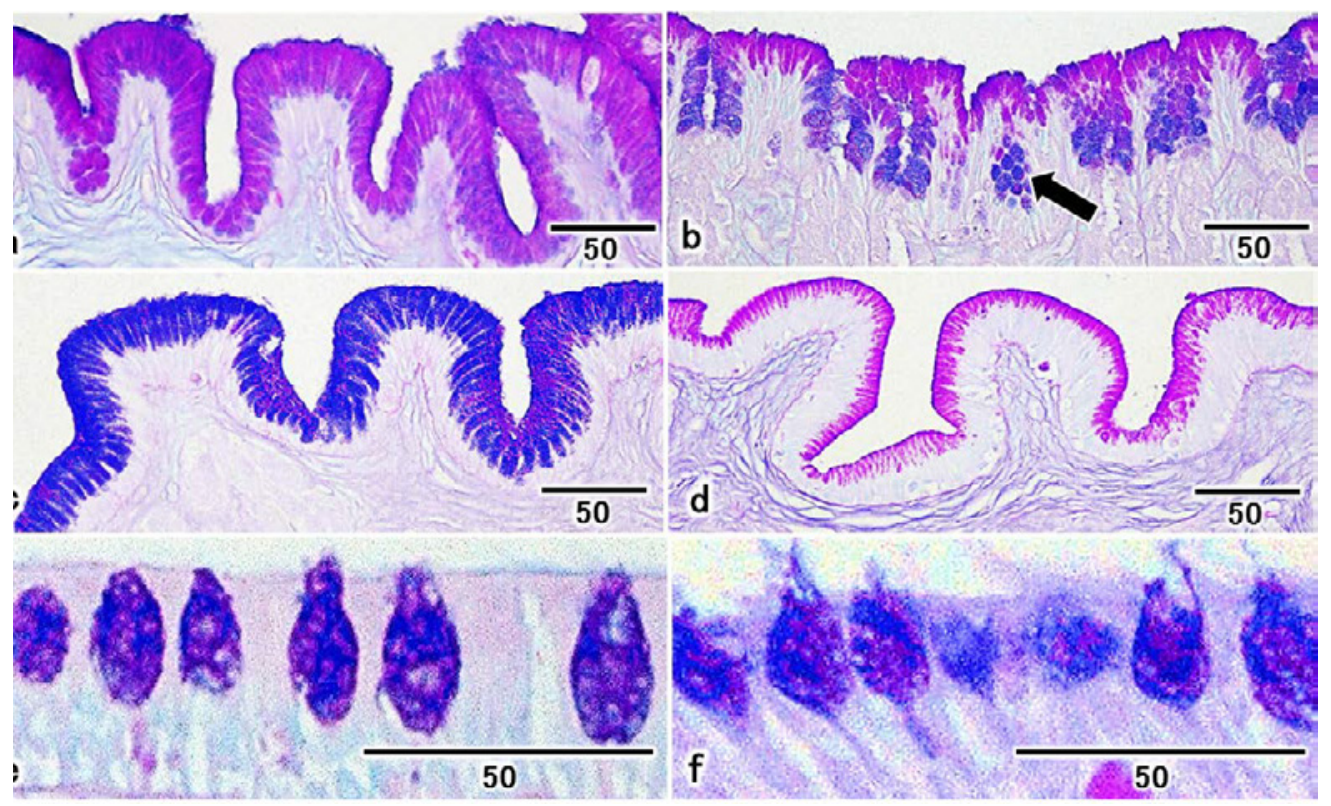

Figure 5: Histochemical observation in the stomach and the intestine. AB/PAS stain.

(a) The cardiac region of the stomach. The gastric surface epithelial cells stained red-purple. Scale bar=50 $\mu$ m. (b) The body region of the stomach. The gastric surface epithelial cells stained red-purple. The neck cells of gastric pits (arrow) stained blue. Scale bar=50 $\mu \mathrm{m}$. (c) The terminal region of the stomach. The gastric surface epithelial cells stained blue-purple. Scale bar $=50 \mu \mathrm{m}$. (d) The pyloric region of the stomach. The gastric surface epithelial cells stained red. Scale bar $=50 \mu \mathrm{m}$. (e) The anterior region of the intestine. The mucus within all goblet cells stained blue-purple. Scale bar=50 $\mu \mathrm{m}$. (f) The posterior region of the intestine. The mucus within all goblet cells stained blue-purple. Scale bar=50 $\mu \mathrm{m}$ 
the epithelial cells have neutral mucus, while the gastric pits contain acidic mucus in the body region of stomach (Figure $5 b$ ). In the terminal region of stomach, the epithelial cells stained purple, demonstrating the presence of a mixture of both acidic and neutral mucus (Figure 5c), and the epithelial cells in the pyloric region of stomach stained red, indicating the presence of neutral mucus Figure $5 \mathrm{~d}$.

In the anterior and posterior intestine, all goblet cells were stained blue-purple by $\mathrm{AB} / \mathrm{PAS}$ staining, indicating that these cells were filled with a mixture of both acidic and neutral mucus (Figure $5 \mathrm{e}$ and $5 \mathrm{f}$ ).

\section{Discussion}

The composition of the digestive tract of C. myriaster was typical of the Elopomorpha Anguilliformes. However, compared to the findings of other current research on the three suborders of Anguilliformes, the histological structure was different despite having the same basic components.

The stomach of C. myriaster was histologically quite characteristic, and was divided into the four regions: cardiac, body, terminal, and pyloric. Furthermore, the inner longitudinal striated muscle layer of the esophagus was contiguous with to the body region of the stomach, and the muscularis in these regions was composed of three layers. This study is the first to report the existence of a striated muscle layer within a body region of the stomach in teleosts, including the Anguilliformes.

In the esophagus, the mucosal epithelium was characterized by stratified cells and numerous goblet cells, fingerprint-like microridges on the apical surface of epithelial cells, and striated muscularis, which is consistent with the features of the esophagus reported for other species of Anguilliformes $[9,14,15]$. Based on histological studies, these features are known to be well suited to the transport of food. Microridges on the apical surface of stratified mucosal epithelial cells may serve to protect the mucosa from mechanical trauma [15-17], and mucus from numerous goblet cells can serve as a protective barrier against hard and rough food as well as a lubricant for helping in the movement of food $[18,19]$. The esophagus is composed of two layers of striated muscularis; an inner longitudinal layer and an outer circular layer. These layers have been reported in the Anguilliformes [15] and Siluriformes $[20,21]$ as being capable of rejecting ingested materials [21]. Interestingly, it should be noted that the inner longitudinal muscle layer of the esophagus was continuous to within the body region of the stomach. On the other hand, the outer circular layer terminated, and became coincident to the boundary of the outer longitudinal layer consisting of smooth muscle in the cardiac region of the stomach, the running direction of striated muscle layers were different. There are no reports of striated muscles continuing to within the body region of the stomach, but this structure makes it easier to reject ingested materials more easily.

These esophageal features were reported not only in the teleosts that branched off more recently than Elopomorpha but also in groups that branched off prior to Elopomorpha, such as Elasmobranchii [22] and Chondrostei [23]. However, some teleosts species possess pharyngeal teeth that aid in the mastication of ingested food [6]. Additionally, species moving to waters of differing salinity show morphological changes in the esophageal mucosal epithelium during adaptation to water with greater salinity [14]. In this way, the morphological features of the esophagus are known to be transformed concomitantly with changing physiological and ecological factors, and although the detailed determination of the function of the striated longitudinal muscle layer within the body region of the stomach remains to be clarified, the relationship among these factors could be hypothesized.
The terminal region of the stomach was similar to that of the Muraenidae, in that it lacked gastric glands and possessed thick longitudinal muscularis and subserosa. The following functional mechanism of this region was proposed by Takiue and Akiyoshi: when large food items enter the stomach, the longitudinal muscle cells in the terminal region relax in order to accommodate the food, and after the food has been sufficiently digested, the longitudinal muscle cells in the terminal region contract and transport the digesta to the pyloric region [8]. The absence of gastric glands in the terminal region may be related to the need for significant relaxation and contraction of longitudinal muscles in this region.

The intestine in the posterior region of digestive tract had a distinctive histological structure in that it was intermediate between the Anguillidae and Muraenidae. The partition-like mucosal fold was the only one fold present in C. myriaster, but it was found in several places in G. pictus [8], and was absent in Anguilloidei [12]. The ciliated cells within the intestinal wall were also observed in C. myriaster, but at a density that was lower than in G. pictus. We previously proposed that the partition-like mucosal folds in G. pictus may have a similar function to the spiral valve that is observed in the group and which is ancestral to basal teleosts. We reported that the ciliated cells within the partitionlike mucosal folds play a critical role in the passage of digesta [8].

That the secretion of mucus is mainly a function of the digestive tract in C. myriaster is interesting. In mucus within the gastric surface mucous cells, neutral mucus was abundant in C. myriaster, and $G$. pictus basically secreted acidic mucus [8]. In contrast, acidic mucus predominates in the terminal region of the stomach inC. myriaster same as G. pictus, and it also indicated the histochemically special aspect of this region which lack in other teleosts. The intestine in $C$. myriaster secrets both acidic and neutral mucus throughout all regions. Anguilla Anguilla $[9,10]$ and Anguilla japonica [13] also produced both acidic and neutral mucus, but G. Pictus solely secretes acidic mucus [8], suggesting that differences in digestive function may exist among suborders.

Mucus secreted into the mucosal epithelial surface plays an important role in protecting the digestive tract against chemical $[17,24,25]$ and mechanical damage $[26,27]$, and it is also involved in osmoregulation [28,29], digestion [30,31], and absorption [32]. Mucus is divided into acidic and neutral types depending on the glycoprotein it contains [33], and the amounts of each glycoprotein in the mucus differ between different regions of the digestive tract. Differences in the distribution of acidic and neutral mucus determine the chemical environment of lumen as well as differences in the chemical functions of different gut regions [34]. Generally, the stomach of teleosts maintains an acidic environment in the lumen and secretes neutral mucus to protect the mucosal surface. The intestine produces both acidic and neutral mucus in order to achieve optimal activation of various digestive enzymes. Acidic mucus suppresses the degradation of the mucus by proteases or bacteria [33] and aids in the absorption of digesta smaller than water-soluble molecules by increasing mucus viscosity and adhesion [32]. Acidic mucus may also contribute to the formation of an acidic environment on the luminal surface. The activity of the acidic protease pepsin is highest in strongly acidic environments [35]. Furthermore, Pérez-Jiménez et al. [36] suggested that lysosomal protease groups, such as cathepsin, might be prevalent in low $\mathrm{pH}$ regions of the pyloric caeca and intestine in Dentexdentex. Neutral mucus is combined with sites of alkaline phosphatase together they facilitate digestion [9] and, in conjunction with microvilli, they may have an absorptive function in enterocytes [30]. The maintenance of a neutral environment at the luminal surface is considered to form an 
Citation: Takiue S, Akiyoshi H (2014) Histological and Scanning Electron Microscopic Examination of the Digestive Tract in Whitespotted Conger, Conger Myriaster (Anguilliformes). J Phylogen Evolution Biol 2: 125. doi:10.4172/2329-9002.1000125

ecological niche for bacteria responsible for the production of specific vitamins or digestive enzyme [37]. In Elopomorpha, the finding that the intestines of the Congridae and Anguillidae synthesized both acidic and neutral mucus, whereas those of Muraenidae secreted only acidic mucus is interesting. Indeed, in addition to ecological factors such as food habits, these differences in mucous production could be used to infer the phylogenetic relationships among these taxa.

The observation that the terminal region of the stomach was similar between G. pictus and C. myriaster suggests that this region is characteristic of Anguilliformes. In addition, this terminal region may also be related to the absence of the pyloric caeca in the Anguilliformes. On the other hand, several distinguishing characteristics were identified among Anguillidae, Muraenidae and Congridae, including the presence of a striated muscle layer within the body region of the stomach, the partition-like mucosal folds and ciliated cells within the intestinal wall, and the relative proportion of the different glycoproteins that compose the mucus secreted into the digestive tract. In particular, it was found that the striated muscle that was continuous from the esophagus to the body region of the stomach was a morphological structure that was unique among the Anguilliformes. These differences in stomach suggested the possible existence of morphological differences that originate from phylogenetic position among the orders in Elopomorpha.

\section{References}

1. Robins CR (1989) The phylogenetic relationships of the anguilliform fishes. Fishes of the western North Atlantic. Orders Anguilliformes and Saccopharyngiformes 1: 9-23.

2. Nelson JS (1994) Fishes of the World (Edn 3) Wiley, New York.

3. Inoue JG1, Miya M, Tsukamoto K, Nishida M (2004) Mitogenomic evidence for the monophyly of elopomorph fishes (Teleostei) and the evolutionary origin of the leptocephalus larva. Mol Phylogenet Evol 32: 274-286.

4. Inoue JG, Miya M, Tsukamoto K, Nishida M (2001) Complete mitochondrial DNA sequence of Conger myriaster (Teleostei: Anguilliformes): novel gene order for vertebrate mitochondrial genomes and the phylogenetic implications for anguilliform families. J Mol Evol 52: 311-320.

5. Hossain AM, Dutta HM (1996) Phylogeny, ontogeny, structure and function of digestive tract appendages (caeca) in teleost fish. Fish Morphology Horizon of New Research. 59-76.

6. Kimura S (2010) New atlas of fish anatomy (Edn 1) Midori Shobo Publishing, Tokyo.

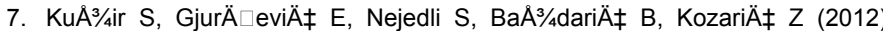
Morphological and histochemical study of intestine in wild and reared European eel (Anguilla anguilla L.). Fish Physiol Biochem 38: 625-633.

8. Takiue S, Akiyoshi H (2013) Light and scanning electron microscope examination of the digestive tract in peppered moray eel, Gymnothorax pictus (Elopomorpha). Anat Rec (Hoboken) 296: 443-451.

9. Clarke AJ, Witcomb DM (1980) A study of the histology and morphology of the digestive tract of the common eel (Anguilla anguilla). J Fish Biol 16: 159-170.

10. Domeneghini C, Arrighi S, Radaelli G, Bosi G, Veggetti A (2005) Histochemical analysis of glycoconjugate secretion in the alimentary canal of Anguilla anguilla L. Acta Histochem 106: 477-487.

11. Ostos-Garrido MV, González Oller C, Abaurrea Equisoain MA (1996) Effect of diet on gastric mucosa cells in the European eel (Anguilla anguilla L.) Histochemical and ultrastructural study. Micron 27: 25-34.

12. Kim YK, Ideuchi H, Watanabe S, Park SI, Huh Md, et al. (2008) Rectal wate absorption in seawater-adapted Japanese eel Anguilla japonica. Comp Biochem Physiol A Mol Integr Physiol 151: 533-541.

13. Yamada K (1975) Morphochemical analysis of mucosubstances in some epithelial tissues of the eel (Anguilla japonica). Histochemistry 43: 161-172.

14. Yamamoto $M$, Hirano $T$ (1978) Morphological changes in the esophageal epithelium of the eel, Anguilla japonica, during adaptation to seawater. Cell Tissue Res 192: 25-38.
15. Abaurrea-Equisoain MA Ostos-Garrido MV (1996) Cell types in the esophageal epithelium of Anguilla anguilla (Pisces, Teleostei). Cytochemical and ultrastructural characteristics. Micron $27: 419-429$.

16. Ezeasor DN, Stokoe WM (1980) Scanning electron microscopic study of the gut mucosa of the rainbow trout Salmo gairdneri Richardson. J Fish Biol 17: 529-539.

17. Carrassón M, Grau A, Dopazo LR, Crespo S (2006)A histological, histochemical and ultrastructural study of the digestive tract of Dentex dentex (Pisces, Sparidae). Histol Histopathol 21: 579-593.

18. Albrecht MP, Ferreira MFN, Caramaschi EP (2001) Anatomical features and histology of the digestive tract of two related neotropical omnivorous fishes (Characiformes; Anostomidae). J Fish Biol 58: 419-430.

19. Leknes IL (2011) Histochemical studies on mucin-rich cells in the digestive tract of a teleost, the Buenos Aires tetra (Hyphessobrycon anisitsi). Acta Histochem 113: 353-357.

20. Sis RF, Ives PJ, Jones DM, Lewis DH, Haensly WE (1979) The microscopic anatomy of the oesophagus, stomach and intestine of the channel catfish Ictalurus punctatus. J Fish Biol 14: 179-186.

21. Cao XJ, Wang WM (2009) Histology and mucin histochemistry of the digestive tract of yellow catfish, Pelteobagrus fulvidraco. Anat Histol Embryol 38: 254261.

22. Chatchavalvanich K, Marcos R, Poonpirom J, Thongpan A, Rocha E (2006) Histology of the digestive tract of the freshwater stingray Himantura signifer Compagno and Roberts, 1982 (Elasmobranchii, Dasyatidae). Anat Embryol (Berl) 211: 507-518.

23. Domeneghini C, Arrighi S, Radaelli G, Bosi G, Mascarello F (1999) Morphological and histochemical peculiarities of the gut in the white sturgeon, Acipenser transmontanus. Eur J Histochem 43: 135-145.

24. Ferraris RP, Tan JD, De La Cruz MC (1987) Development of the digestive tract of milkfish, Chanos chanos (Forsskal): Histology and histochemistry. Aquaculture 61: 241-257

25. Scocco P, Ceccarelli P, Mengh G (1996) Glycohistochemistry of the Tilapia spp. Stomach. J Fish Biol 49: 584-593.

26. Manjakasy JM, Day RD, Kemp A, Tibbetts IR (2009) Functional morphology of digestion in the stomachless, piscivorous needlefishes Tylosurus gavialoides and Strongylura leiura ferox (Teleostei: Beloniformes). J Morphol 270: 11551165.

27. Diaz AO, Escalante AH, García AM, Goldemberg AL (2006) Histology and histochemistry of the pharyngeal cavity and oesophagus of the silverside Odontesthes bonariensis (Cuvier and Valenciennes). Anat Histol Embryol 35: 42-46.

28. Simonneaux V, Humbert W, Kirsch R (1987) Mucus and intestinal ion exchanges in the sea-water adapted eel,Anguilla anguilla L. J Comp Physio B 157: 295-306.

29. Díaz AO, García AM, Goldemberg AL (2008) Glycoconjugates in the mucosa of the digestive tract of Cynoscion guatucupa: a histochemical study. Acta Histochem 110: 76-85.

30. Grau A, Crespo S, Sarasquete MC, De Canales MLG (1992) The digestive tract of the amberjack Seriola dumerili, Risso: a light and scanning electron microscope study. J Fish Biol 41: 287-303.

31. Anderson TA (1986) Histological and cytological structure of the gastrointestinal tract of the luderick, Girella tricuspidata (pisces, kyphosidae), in relation to diet. J Morphol 190: 109-119.

32. Tibbetts IR (1997) The distribution and function of mucous cells and their secretions in the alimentary tract of Arrhamphus sclerolepis krefftii. J Fish Biol 50: 809-820.

33. Neuhaus M, Der MN, Caspari W, Meyer M, Enss L, et al. (2007) Biochemica and histochemical study on the intestinal mucosa of the common carp Cyprinus carpio L., with special consideration of mucin glycoproteins. J Fish Biol 70 : 1523-1534.

34. Domeneghini C, Ponnelli Straini R, Veggetti A (1998) Gut glycoconjugates in Sparus aurata L. (Pisces, Teleostei). A comparative histochemical study in larval and adult ages. Histol Histopathol 13: 359-372

35. Xiong DM, Xie CX, Zhang HJ, Liu HP (2011) Digestive enzymes along digestive tract of a carnivorous fish Glyptosternum maculatum (Sisoridae, Siluriformes). $J$ Anim Physiol Anim Nutr (Berl) 95: 56-64. 
Citation: Takiue S, Akiyoshi H (2014) Histological and Scanning Electron Microscopic Examination of the Digestive Tract in Whitespotted Conger, Conger Myriaster (Anguilliformes). J Phylogen Evolution Biol 2: 125. doi:10.4172/2329-9002.1000125

Page 8 of 8

36. Pérez-Jiménez A Cardenete G, Morales AE, García-Alcázar A, Abellán E, et al. (2009) Digestive enzymatic profile of Dentex dentex and response to different dietary formulations. Comp Biochem Physiol A Mol Integr Physiol 154: 157-164.
37. Fiertak A, Kilarski WM (2002) Glycoconjugates of the intestinal goblet cells of four cyprinids. Cell Mol Life Sci 59: 1724-1733. 